\title{
Sterile Field Contamination by Elastomeric Respirators Versus Surgical Masks and N95s
}

Brittany Howard ( $\square$ howard.brittany@mayo.edu )

Mayo Clinic Arizona

Ryan Thorwarth

Mayo Clinic Arizona

Karam Karam

Arizona State University

Sam Snider

Mayo Clinic Arizona

Erica Forzani

Arizona State University

Joseph Hentz

Mayo Clinic Arizona

Erin Graf

Mayo Clinic Arizona

Bhavesh Patel

Mayo Clinic Arizona

Kelly McKay

Mayo Clinic Arizona

Michael Hinni

Mayo Clinic Arizona

Devyani Lal

Mayo Clinic Arizona

\section{Biological Sciences - Article}

Keywords: sterile field contamination, elastomeric respirators, surgical masks, n95, infectious aerosol particles

Posted Date: September 24th, 2020

DOI: https://doi.org/10.21203/rs.3.rs-81198/v1

License: (1) (1) This work is licensed under a Creative Commons Attribution 4.0 International License. Read Full License 
Page $2 / 19$ 


\section{Abstract}

Background: Elastomeric respirators are reusable and reliable protection from infectious aerosol particles such as SARS-CoV-2. There is a lack of safety data for use in sterile fields limiting application to operating room settings where high-risk aerosol generating procedures are performed. We hypothesized an equivalent reduction in sterile field contamination would be achieved using an elastomeric respirator covered by a surgical mask as compared to a standard surgical mask or N95.

Methods: Randomized controlled crossover experiment with repeat measurement comparing microbial and aerosol contamination of operating room surfaces for elastomeric respirators, elastomeric respirators covered by a surgical mask, N95, surgical mask, and no mask. 80 experiments were performed by participants with randomized order and balanced crossover to all masking groups ( $n=16$ per masking group). Participants executed droplet and aerosol generating procedures while wearing: (Group 1) elastomeric respirator with mask, (Group 2) elastomeric respirator only, (Group 3) N95, and (Group 4) surgical mask. Positive control was established with the participant unmasked (Group 5). Contamination was measured by microbial growth on settling plates and optical particle counters $(0.2+$ and 2 um+ particles).

Results: There was a reduction in microbial contamination at the sterile field $(p<0.001)$ for all masks (Groups 1-4) compared to unmasked (Group 5). The mean colony forming units (CFU) at the sterile field was 0 CFUs for elastomeric respirator (+/- mask), N95, and surgical mask versus unmasked growing $1.875 \mathrm{CFUs}$. Compared to the unmasked control, the elastomeric respirator (+/- mask), N95, and surgical masks all resulted in a -0.75 difference in contamination $(95 \% \mathrm{Cl}-0.91$ to $-0.48, p<0.001)$. No significant difference in contamination between the elastomeric respirator (+/- mask) and a surgical mask was detected. No significant difference in particle counts $(0.2 \mu \mathrm{m}+$ and $2.0 \mu \mathrm{m}+)$ between the elastomeric respirator (+/- mask) and a standard surgical mask.

Conclusion and Relevance: Elastomeric respirators with or without mitigation are as effective as a surgical mask and $\mathrm{N} 95$ for reducing contamination at the sterile field in an operating room. Consideration should be given to expanding the use of elastomeric respirators to operating rooms during high-risk aerosol generating procedures.

\section{Summary}

Identifying reliable, safe respiratory protection equipment for healthcare workers has become a major focus during the COVID-19 pandemic caused by SARS-CoV-2. Elastomeric half mask respirators are reusable, durable respirator option that can provide greater protection to the wearer than a N95. Given their reusable nature, a single respirator can provide a full year of respiratory protection to a healthcare worker at a fraction of the cost of disposable N95s. ${ }^{1,2}$ However, their use in healthcare settings has been limited by concern for contamination of sterile fields by the exhalation valve on the elastomeric respirator. Here we show in a randomized, controlled cross-over trial that elastomeric respirators protect operating 
room sterile fields from microbial contamination to a similar level as surgical masks and surgical N95s. Additionally, there is no measurable difference in aerosol contamination of sterile fields between elastomeric respirators, surgical masks, and N95s. Our results demonstrate that elastomeric respirators can be considered as an option for healthcare worker respiratory protection in sterile field environments and consideration should be given to expanding their use in healthcare settings. This is of significance throughout healthcare and especially in areas where obtaining a reliable supply of N95s is difficult or cost prohibitive. We anticipate this paper to be a starting point for future research into the use of elastomeric respirators in diverse healthcare settings including clinical, procedural, and hospitals worldwide.

\section{Introduction}

Identifying options for healthcare worker $(\mathrm{HCW})$ respiratory protection during aerosol generating procedures (AGPS) such as intubation, tracheotomy, and aero-digestive procedures on patients with COVID-19 from acute respiratory syndrome coronavirus 2 (SARS-CoV2) has become an area of significant focus. Powered air-purifying respirators/controlled air-purifying respirators (PAPRs/CAPRs) and single-use N95 masks are currently the primary form of respiratory PPE used in United States institutions for high-risk AGPs on COVID-19 and high-risk/untested patients. N95 respirators filter at least $95 \%$ of particles $>0.3 \mu \mathrm{m}$ and are the minimum level of respiratory personal protective equipment (PPE) recommended by the Centers for Disease Control (CDC) for use in AGPs. ${ }^{1}$ However, supply chain issues have resulted in shortages and difficulty obtaining adequate quantities of N95s for HCW protection. PAPRs/CAPRs are a reusable option for respiratory PPE but are difficult to use by surgeons/proceduralists that need to use microscopes, loupes, headlights, etc. A third option for respiratory protection is elastomeric half-mask respirators (EHMR) fitted with filters ranging from N95 to P100 (certified to filter $99.97 \%$ of $0.3 \mu \mathrm{m}$ particles). ${ }^{2}$ EHMRs have the favorable features of reusability, durability, and potential higher-level protection compared to disposable N95 respirators. This has recently resulted in attention and adoption of EHMRs across some U.S. healthcare systems. ${ }^{3}$ In contrast to N95s which filter both inhaled and exhaled air, EHMRs filter inhaled air but exhaled air is emitted unfiltered through a one-way valve. The EHMR exhalation valve reduces humidity, heat, and carbon dioxide retention within the respirator, resulting in improved comfort and decreased physiologic demands on the wearer. ${ }^{4-6}$ However, the lack of filtration at the exhalation valve has raised concerns for the use of EHMRs in sterile fields. As a result, the CDC does not recommend EHMRs when sterility needs to be maintained. ${ }^{7}$ Nxo published studies on EHMRs have reliably investigated the risk of contamination of sterile fields, or acceptable mitigation strategies.

This study was designed as a randomized controlled crossover experiment to compare sterile field contamination by EHMRs (with and without mitigation) versus the standard of care surgical masks and N95s in an operating room setting. The hypothesis was that EHMRs covered by a surgical mask would provide equivalent protection to the sterile field as a surgical mask or N95. Secondary endpoints included: reduction in contamination at the anesthesia field, reduction in contamination at the nursing field, and difference in contamination between EHMR, EHMR covered with a surgical mask (EHMRwM), N95, and a 
surgical mask. Participants performed aerosol generating activities in an operating room setting for 10 minutes while wearing either EHMR, EHMRwM, N95, surgical mask or no mask; during this time contamination throughout the room by droplets and aerosols was measured (Figure 1).

\section{Results}

Operating room characteristics

The room baseline characteristics included temperature mean $19.53(95 \% \mathrm{Cl} 18.99$ - 20.07) degrees Celsius with mean $27.49 \%(95 \% \mathrm{Cl} 23.88-31.09 \%)$ relative humidity, and mean 959.6 (95\% Cl 958.31 960.99) $\mathrm{hPa}$ pressure. The air flow within the operating room across duration of experiments averaged $28.77(95 \% \mathrm{Cl} 23.51-34.02) \mathrm{ACH}$.

Microbiology Results

During the experiment, overall incidence of contamination by colonization occurred at the sterile field $12 / 80$ (15\%), anesthesia field $2 / 80(2.5 \%)$, and nursing field $3 / 16$ (3.75\%). The incidence of colonization at the sterile field was $0 / 16$ for EHMRwM, 0/16 for EHMR, 0/16 for N95, 0/16 for surgical mask, and $12 / 16$ for unmasked (Figure 2). There was statistically significant difference in the microbial contamination between masking groups using the Pearson chi-square test. The incidence of contamination was significantly reduced for EHMRwM, EHMR, N95, and the surgical mask compared to the unmasked control $(P<0.001)$.

Contamination occurred more frequently in the sterile field than the anesthesia or nursing locations. Contamination data at the anesthesia and nursing field are shown in Table 1. There was no statistically significant difference in the microbial contamination between masking groups at these individual locations. Combining all locations, unmasked showed EHMRWM and N95s showed 1 colonization per 16 experiments, EHMR showed 1 colonization per 8 experiments, and surgical masks showed no colonization. The differences were not statistically significant, and no colonization occurred at the sterile field with any mask (Group 1-4).

Particle Results

The mean total particles size $0.2 \mathrm{~mm}+$ and $2 \mathrm{~mm}+$ for each masking group at the sterile field, anesthesia field, and nursing field are shown in Table 2 . There was no statistically significant difference in number of $0.2 \mathrm{~mm}+$ and $2.0 \mathrm{~mm}+$ particles produced between the EHMRWM, EHMR, N95, surgical mask, and the unmasked scenarios. This was true for all locations tested (sterile field, anesthesia field, and nursing field) for $0.2 \mu \mathrm{m}+$ and $2.0 \mu \mathrm{M}+$ particles (Figure 3).

Comparing Microbiology and Particle Results:

Particle concentration was not associated with microbial contamination. Mean particle counts for tests with contamination $\left(0.2 \mu \mathrm{m}+\right.$ particles $=900(\mathrm{std}=1500)$ count $/ \mathrm{feet}^{3} ; 2.0 \mu \mathrm{m}+$ particles $=59($ std 83$)$ 
count $/$ feet $\left.^{3}\right)$ and those without contamination $\left(0.2 \mu \mathrm{m}+\right.$ particles $=1000$ (std 1800) count/feet ${ }^{3} ; 2.0 \mu \mathrm{m}+$

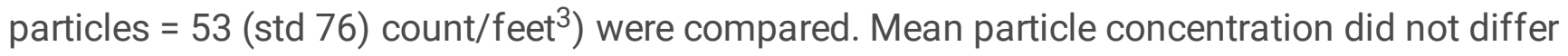
substantially between runs based on microbial contamination. The particle concentration measurements might not serve well as a surrogate measure for risk of infection. Their significance related to viral contamination is unknown.

\section{Discussion}

During the COVID-19 pandemic, protecting HCW from infectious aerosols with appropriate respiratory PPE is imperative but has become challenging. A goal of zero nosocomial COVID-19 infections amongst $\mathrm{HCW}$ is an essential to maintain the workforce and its morale. EHMRs can provide reliable and potentially enhanced respiratory protection compared to the N95 respirator, especially for healthcare workers performing high-risk APGs on a recurrent or regular basis. EHMRs may be of greatest benefit in the operating room where long procedures with high-risk AGP may be commonly performed by anesthesiologists, otolaryngologists, thoracic surgeons, pulmonologists, gastroenterologists, etc.

This study is the first to evaluate the safety of EHMRs in sterile field settings. Our study did not find the exhalation valve to cause statistically significant increased droplet or aerosol creation in comparison to a standard surgical mask or N95. Compared to unmasked baseline, there was significant reduction in contamination at the sterile field when a participant was wearing an EHMRWM, EHMR, N95, or surgical mask. The use of any mask (N95, surgical or EHMRs \pm surgical mask) resulted in elimination of detectable microbial contamination at the sterile field. Significantly, there was no detectable difference in contamination of the sterile field when comparing a standard surgical mask to the EHMR, irrespective of whether the EHMR was covered. This finding supports that EHMRs may be safely used in an operating room environment without risking microbial contamination of the sterile field.

An unexpected finding was the significant reduction in contamination created by use of an EHMR alone, even without mitigation by a covering surgical mask. This may be related to the internal shape of the EHMR; the chin piece of the mask covers or partially occludes the exhalation valve area. As a result, the exhaled air stream must move around multiple bends within the mask prior to reaching the exhalation valve. Droplets may be collected within the EHMR by inertial impaction wherein droplets above a certain size are unable to make the bend with the airstream and impact the surface of the mask rather than escaping via the exhalation valve. ${ }^{8-9}$ This inertial impaction of droplets within the mask would prevent them from reaching and exiting the mask through the exhale valve. Droplets ${ }^{3} 1$ micrometers may be stopped by this mechanism, including bacterial and viral droplet nuclei. ${ }^{10}$ Inertial impaction of droplets within the mask could explain the findings of reduced contamination at the sterile field by the EHMR compared to an unmasked situation although additional modeling is needed.

The findings of this study have significant ramifications for respiratory protection programs for health care workers. Currently, the CDC provides guidance for the use of EHMRs for protection from infectious droplets and aerosol, with the exception that EHMRs are not appropriate for use in sterile fields. This 
study provides evidence that EHMRs may be used in operating room settings without increased risk of sterile field contamination. As EHMRs are reusable, can provide higher levels of protection, and are more cost effective compared to N95 masks, their potential use has significant ramifications for healthcare worker protection. ${ }^{2}$ This is especially true in areas where disposable N95s or PAPRs/CAPRs are limited by supply or cost.

It is reasonable to cover the EHMRs exhalation valve with a surgical mask. Surgical masks protect HCWs from splashes and the patient from droplets and aerosols exhaled by the surgeon. The mitigation technique of covering an EHMR with a surgical mask showed no difference in sterile field contamination compared to a standard surgical mask, supporting its safety. The lack of difference for microbial contamination between EHMRwM versus EHMR alone, is not surprising as prior systematic review of the literature failed to show association between surgical masks and reduction in surgical site infections. ${ }^{11-12}$ Although surgical masks are cleared by the FDA with the intention of protecting the local environment from the wearer's exhaled breath, the certification testing is performed in-vitro and its correlation to live procedural scenarios is not established. Despite this, the continued use of surgical masks has been warranted as they provide protection to the surgeon from splashes, pose no danger to the patient, and may provide some as yet unmeasured benefit to the patient. Similarly, although our study found no measurable reduction in sterile field contamination between the EHMRWM versus EHMR alone, the use of a surgical mask cover over the EHMR during sterile procedures is reasonable to provide additional protection to the patient and to prevent accidental splash/soiling of the respirator itself.

Participant "surgeons" in the study included an attending surgeon, a resident surgeon, a licensed surgical physician assistant, and a medical student. Therefore, the results can be extrapolated to members of a standard surgical team that are familiar with aseptic technique and use of personal protective equipment in accordance with national guidelines. At our home institution, the EHMRwMs have been used in "cleancontaminated" otolaryngology high-risk APGs. It is of significance that there has been no hospital acquired COVID-19 infections in the personnel or patients with this use, albeit in association with other precautions which enhance safety.

There was no significant difference for particle generation $(0.2$ and $2.0 \mu \mathrm{m}+)$ between the EHMR groups, $\mathrm{N} 95$, and the surgical mask group. Particle sizes $0.2 \mu \mathrm{m}+$ and $2.0 \mu \mathrm{m}+$ were selected to represent a range of viral and bacterial droplet nuclei associated with prolonged suspension in air (2-12 hours) and thus unlikely to be detected by settling plates. The absence of difference between masking groups may relate to high $\mathrm{ACH}$ of the operating rooms where rapid air turnover creates prompt dilution of aerosol particles. The measured air handling within the operating rooms was higher (average $28.77 \mathrm{ACH} ; 95 \% \mathrm{Cl} 23.51-$ 34.02) than the $15-20 \mathrm{ACH}$ recommended by national guidelines, but in line with national normal ranges of $15-40 \mathrm{ACH}$ for operating rooms. ${ }^{13-14}$ This high lambda results in approximately 0.5 air changes per minute with removal of $90 \%$ of airborne contaminants in 5 minutes. Prior data supports that increased $\mathrm{ACH}$ is associated with reduction in contamination of air. ${ }^{15}$ Additionally, the testing conditions were 10 minutes of measurement with greater than $50 \%$ of that time being non-exertional breathing. This is representative of real-life scenarios and clinically applicable. However, aerosol particle size and 
distribution has been shown to vary with expiratory activities and the high percentage of time spent with non-exertional breathing may have resulted in normalization of aerosol data across the test groups. ${ }^{16-17}$ Consistent with this, during high aerosol generating events we saw brief spikes of increased particle generation that rapidly returned to baseline. This, in combination with high $\mathrm{ACH}$, may account for our aerosol findings. Future testing that focusing only on aerosol generation should be considered.

There are multiple potential errors in this study's conclusions. The study was powered to detect a reduction in contamination at the sterile field compared to the unmasked baseline. A study with hundreds of tests would be needed to identify potential small differences between the masking groups. Although this study was modeled after prior studies from the CDC with smaller samples, a larger data set would improve the strength of conclusions. ${ }^{18}$ Given the similarity in particle data between all 5 masking groups, a much larger sample focusing only on aerosol generating activities should be performed to potentially detect aerosol generation differences. In this study, only one type of EHMR was tested with a forwardfacing exhalation valve. The forward-facing valve is considered highest risk, but studies looking at EHMRs with inferiorly directed valves are warranted. Additional potential error comes from variation between participants in their performance of experimental tasks, oral/nasal flora, oral hygiene, timing of last meal, etc.

\section{Conclusions}

Elastomeric respirators are feasiable alternatives to surgical N95s when performing high-risk AGPs in the operating room during the COVID-19 pandemic, conforming to the spirit of the CDC guidance on using respiratory protective equipment that provides the maximal level protection to the healthcare worker. This study did not find increased risk of surgical field contamination or aerosolization with an EHMR mask compared to a standard surgical mask or N95.

\section{Methods}

\section{Study design:}

This study was approved by the Mayo Clinic Institutional Review Board. The methodology of this experimental study was adapted from the CDC study on PAPR/CAPRs sterile field contamination. ${ }^{18}$ Experimental design, operating room setup, participant characteristics, testing battery, data collection, and statistical methods are outlined below.

The study was designed as a randomized controlled crossover trial with repeat measurements for a total sample size of 80 . Four participants trialed each mask in randomly assigned order with balanced crossover for a total of 4 repeated measurements per mask. This resulted in 80 experiments distributed to 16 per mask group. The masking variables tested included: (1) EHMR with surgical mask cover (EHMRwM), (2) EHMR (EHMR), (3) N95, (4) surgical mask, and (5) unmasked. For the EHMR, all participants used a Dräger X-Plore ${ }^{\circledR} 3500$ EHMR (Drägerwerk AG \& Co. KGaA, Lübeck, Germany) with 
P100 filter cartridges. The N95s were NIOSH and Food and Drug Administration (FDA) approved. The FDA approved surgical masks used was based on participants daily mask use. The unmasked situation provided a positive control.

\section{Setting:}

A licensed operating room within the institution hospital was utilized. Baseline room conditions were recorded including temperature, relative humidity, and pressure. The air supply was HEPA filtered and airflow was measured using carbon dioxide as a tracer gas. The lambda in each room meet national minimum air exchange rate of $>15-20$ air changes per hour $(\mathrm{ACH}) .^{13}$

The operating room setup included a surgical bed, a Mayo stand placed each of the 3 locations, 33 optical counter sensors (one placed on each of the 3 Mayo stands), and sheep blood agar settling plates (Figure 1). The surgical table was placed 32 inches high. Mayo stands and specimen collection devices were placed at a height of 42 inches based on the average height of males/females in the US and considering surgical loupes with a 16 -inch working distance. ${ }^{19}$ Three Mayo stands were placed as sterile field, anesthesia field, and a nursing field. The sterile field Mayo was immediately in front of the surgeon centered on the OR table. The anesthesia field Mayo stand was at the head of the bed centered 4.5 feet from the center of the sterile field. The nursing field Mayo stand at the foot of the bed had its center 9 feet from the center of the sterile field. Directly in front of the surgeon, and at forty-five degrees to the left and right, a printed passage was posted to indicate where the subject was to turn their head and read during a standard battery of aerosol generating movements.

\section{Experimental Steps:}

For each test, participants wore an impervious surgical gown, sterile gloves, and disposable hair covers. All subjects were fit-tested for EHMR with P100 filters and N95s per OSHA national standards. During each experiment, the participant performed 10 minutes of droplet/aerosol generating activities for each of the 5 mask test groups. The mask test order was randomized. At test initiation, participants walked to the surgical field. Facing forward, they read a standard-length passage ("rainbow passage"), performed two forceful coughs, performed two deep exhales/inhales through the nose, and two deep exhales/inhales through the mouth for a total of two minutes. These maneuvers were then repeated with the head turned 45 degrees to the right ( 2 minutes), head turned 45 degrees to the left ( 2 minutes), and looking directly at the sterile field. To complete the 10 minutes, the participant looked directly at the sterile field while performing normal breathing. After completion, the participant backed away and waited 2 minutes to allow suspended particles to settle onto agar plates. Agar plates were then collected using sterile technique. Between each test, the participant changed their sterile attire and masks while mayo stands and particle counters were disinfected with Oxyvir® solution (Diversity, Inc. Fort Mill, South Carolina, USA).

\section{Microbial Contamination Measurement:}


Microbial contamination was measured using sheep blood agar settling plates in each field during each test. This included 2 agar plates the sterile field (placed side-by-side one centimeter apart), 1 plate at the anesthesia field, and 1 plate at the nursing field. The sheep blood agar plates collected for 12 minutes (10 minutes experiment with 2 minute settling time). This allowed thorough sampling of droplet particles as droplets size $5-100 \mu \mathrm{m}$ would be expected to settle within 5.8 seconds to $<12$ minutes. ${ }^{20}$ After each iteration, the agar plates were collected sterilely and transferred to the main hospital laboratory. The agar plates were incubated per our institutional microbiology laboratory standard at 5\% CO2 at 37 degrees Celsius. Counts of colony-forming units (CFU) were measured at 7 days.

\section{Aerosol Contamination Measurement:}

To measure contamination by aerosol particles, an optical counter sensor (Dylos DC11000 Air Quality Monitor, Dylos Corp., Riverside, California, USA) was placed on each field with the sampling port facing the participant surgeon. The optical counter was previously validated for measurement particles 0.2 $2.0 \mu \mathrm{m}(0.2 \mu \mathrm{m}+)$ and $2.0-10.0 \mu \mathrm{m}(2.0 \mu \mathrm{m}+)$. Measurement of aerosol particles $0.2 \mu \mathrm{m}+$ (viral aerosols) and $2.0 \mu \mathrm{m}+$ (bacterial aerosols) was performed continuously at all 3 locations. Total collection time was 10 minutes for particle data which was analyzed for total particle count during the 10 minute testing time span.

\section{Statistical Analysis:}

Statistical power analyses based on preliminary data and the assumption that reduction of $14 \%$ points was significant (assuming $\mathrm{p}<0.05$ ) as this translated into reduction of 1 colonization per 7 surgeries. Thus, 80 samples were necessary to provide a detectable difference of $p<0.05$. The sample was too small to model the correlation structure among repeated runs by the same simulator. Repeat observations were assumed to behave independently. The incidence of colonization was compared between mask types by using the Pearson chi-square test. The mean particle concentration was compared between runs with and without colonization by using the two-sample t-test. The mean particle concentration was compared between mask types by using one-way ANOVA and the two-sample t-test.

\section{Declarations}

\section{Author Contributions:}

Brittany E. Howard MD: This author has substantially contributed to study design, data acquisition, data analysis, interpretation of data, drafting of the manuscript, manuscript revision, and final manuscript approval. This author also agrees to be accountable for all aspects of the work and has worked to ensure that any questions related to accuracy or integrity have been fully investigated and resolved.

Ryan M. Thorwarth MD: This author has substantially contributed to data acquisition, drafting of the manuscript, manuscript revision, and final manuscript approval. This author also agrees to be 
accountable for all aspects of the work and has worked to ensure that any questions related to accuracy or integrity have been fully investigated and resolved.

Karam Abi Karam BS: This author has substantially contributed to data acquisition, drafting of the manuscript, manuscript revision, and final manuscript approval. This author also agrees to be accountable for all aspects of the work and has worked to ensure that any questions related to accuracy or integrity have been fully investigated and resolved.

Sam L. Snider BS: This author has substantially contributed to data acquisition, drafting of the manuscript, manuscript revision, and final manuscript approval. This author also agrees to be accountable for all aspects of the work and has worked to ensure that any questions related to accuracy or integrity have been fully investigated and resolved.

Erica Forzani PhD: This author has substantially contributed to study design, data acquisition, data analysis, interpretation of data, manuscript revision, and final manuscript approval. This author also agrees to be accountable for all aspects of the work and has worked to ensure that any questions related to accuracy or integrity have been fully investigated and resolved.

Joseph G. Hentz MS: This author has substantially contributed to study design, data analysis, interpretation of data, manuscript revision, and final manuscript approval. This author also agrees to be accountable for all aspects of the work and has worked to ensure that any questions related to accuracy or integrity have been fully investigated and resolved.

Erin H. Graf PhD: This author has substantially contributed to data analysis, interpretation of data, manuscript revision, and final manuscript approval. This author also agrees to be accountable for all aspects of the work and has worked to ensure that any questions related to accuracy or integrity have been fully investigated and resolved.

Bhavesh Patel MD: This author has substantially contributed to study design, data acquisition, manuscript revision, and final manuscript approval. This author also agrees to be accountable for all aspects of the work and has worked to ensure that any questions related to accuracy or integrity have been fully investigated and resolved.

Kelly J. McKay EMT-P: This author has substantially contributed to study design, data acquisition, manuscript revision, and final manuscript approval. This author also agrees to be accountable for all aspects of the work and has worked to ensure that any questions related to accuracy or integrity have been fully investigated and resolved.

Michael L. Hinni MD: This author has substantially contributed to study design, manuscript revision, and final manuscript approval. This author also agrees to be accountable for all aspects of the work and has worked to ensure that any questions related to accuracy or integrity have been fully investigated and resolved. 
Devyani Lal MD: This author has substantially contributed to study design, interpretation of data, manuscript revision, and final manuscript approval. This author also agrees to be accountable for all aspects of the work and has worked to ensure that any questions related to accuracy

\section{Competing Interests Statement:}

Brittany E. Howard MD: This author has no personal or financial competing interests.

Ryan M. Thorwarth MD: This author has no personal or financial competing interests.

Karam Abi Karam BS: This author has no personal or financial competing interests.

Sam L. Snider BS: This author has no personal or financial competing interests.

Erica Forzani PhD: This author has no personal or financial competing interests related to this research. She does have a pending patent application "SYSTEM AND METHOD FOR MITIGATING AIRBORNE CONTAMINATION IN CONDITIONED INDOOR ENVIRONMENTS” E. Forzani, B. Patel, K. McKay, G. Pyznar, Provisional Patent, August, 2020.

Joseph G. Hentz MS: This author has no personal or financial competing interests related to this research. He has previously received grant funding from the Patient-Centered Outcomes Research Institute.

Erin H. Graf PhD: This author has no personal or financial competing interests.

Bhavesh Patel MD: This author has no personal or financial competing interests. He does have a pending patent application "SYSTEM AND METHOD FOR MITIGATING AIRBORNE CONTAMINATION IN CONDITIONED INDOOR ENVIRONMENTS” E. Forzani, B. Patel, K. McKay, G. Pyznar, Provisional Patent, August, 2020.

Kelly J. McKay EMT-P: This author has no personal or financial competing interests. He does have a pending patent application "SYSTEM AND METHOD FOR MITIGATING AIRBORNE CONTAMINATION IN CONDITIONED INDOOR ENVIRONMENTS" E. Forzani, B. Patel, K. McKay, G. Pyznar, Provisional Patent, August, 2020.

Michael L. Hinni MD: This author has no personal or financial competing interests related to this research. He is the inventor of a laryngoscope manufactured and sold by Karl Storz. He receives an honorarium from this.

Devyani Lal MD: This author has no personal or financial competing interests.

\section{Corresponding Author:}

Brittany Howard MD 
Department of Otolaryngology Head and Neck Surgery

5777 E Mayo Blvd Phoenix, AZ 85254

Office Phone: 480-342-2928

Office Fax: 480-342-2626

Howard.brittany@mayo.edu

Data Availability:

The datasets generated during and/or analyzed during the current study are available from the corresponding author on reasonable request

\section{References}

1. Howard, BE. High-Risk Aerosol-Generating Procedures in COVID-19: Respiratory Protective Equipment Considerations. Otolaryngology-Head and Neck Surgery. Epub May 12, 2020. https://doi.org/10.1177/0194599820927335

2. National Academies of Sciences, Engineering, and Medicine; Health and Medicine Division; Board on Health Sciences Policy; Committee on the Use of Elastomeric Respirators in Health Care; Liverman $\mathrm{CT}$, Yost OC, Rogers BME, et al., editors. Reusable Elastomeric Respirators in Health Care: Considerations for Routine and Surge Use. Washington (DC): National Academies Press (US); 2018 Dec 6. 3, Implementing Reusable Elastomeric Respirators in Health Care Settings: Routine and Surge Use. Available from: https://www.ncbi.nlm.nih.gov/books/NBK540080/

3. Hamby C. They evoke darth vader, but these masks may save your doctor's life. New York Times. Published May 27, 2020. Accessed June 30, 2020. https://www.nytimes.com/2020/05/27/us/coronavirus-masks-elastomeric-respirators.html

4. Roberge RJ, Coca A, Williams WJ, Powell JB, Palmiero AJ. Reusable elastomeric air-purifying respirators: Physiologic impact on health care workers. American Journal of Infection Control. 2010;38(5):381-386.

5. Roberge RJ, Coca A, Williams WJ, Powell JB, Palmiero AJ. Reusable elastomeric air-purifying respirators: Physiologic impact on health care workers. American Journal of Infection Control. 2010;38(5):381-386.

6. National Academies of Sciences, Engineering, and Medicine; Health and Medicine Division; Board on Health Sciences Policy; Committee on the Use of Elastomeric Respirators in Health Care; Liverman $\mathrm{CT}$, Yost OC, Rogers BME, et al., editors. Reusable Elastomeric Respirators in Health Care: Considerations for Routine and Surge Use. Washington (DC): National Academies Press (US); 2018 Dec 6. 2, Elastomeric Respirators. Available from: https://www.ncbi.nlm.nih.gov/books/NBK540078/ 
7. Centers for Disease Control and Prevention. Elastomeric respirators: strategies during conventional and surge demand situations: conventional, contingency, and crisis strategies. Coronoavirus Disease 2019 (COVID-19). Published April 20, 2020. Accessed June 7, 2020.

https://www.cdc.gov/coronavirus/2019-ncov/hcp/elastomeric-respirators-strategy/index.html

8. Holton PM, Tackett DL, Willeke K. Particle size-dependent leakage and losses of aerosols in respirators, Am Ind Hyg Assoc J, 1987, vol. 48 (pg. 848-54)

9. Tcharkhtchi A, Abbasnezhad N, Zarbini Seydani M, Zirak N, Farzaneh S, Shirinbayan M. An overview of filtration efficiency through the masks: Mechanisms of the aerosols penetration. Bioactive Materials. 2021;6(1): 106-122.

10. Janssen L. Principles of physiology and respirator performance, Occup. Health Saf, 2003;72(6): 7381

11. Vincent M, Edwards P. Disposable surgical face masks for preventing surgical wound infection in clean surgery. Cochrane Database of Systematic Reviews 2016, Issue 4. Art. No.: CD002929. DOI: 10.1002/14651858.CD002929.pub3

12. Romney MG. Surgical face masks in the operating theatre: reexamining the evidence. $J$ Hosp Infect 2001; 47: 251-6.

13. Sehulster L, Chinn RYW, CDC, HICPAC. Guidelines for environmental infection control in health-care facilities. Recommendations of CDC and the Healthcare Infection Control Practices Advisory Committee (HICPAC). MMWR Recomm Rep Morb Mortal Wkly Rep Recomm Rep. 2003;52(RR-10):142.

14. Centers for Disease Control and Prevention. Appendix B. Air: Guidelines for environmental infection control in health-care facilities (2003). Infection control. Published July 22, 2019. Accessed May 30, 2020.

https//www.cdc.gove/infectioncontrol/guidelines/environmental/appendix/air.htm\#table2lean surgery. Cochrane Database of Systematic Reviews 2016, Issue 4. Art. No.: CD002929. DOI: 10.1002/14651858.CD002929.pub3

15. Vonci N, De Marco MF, Grasso A, Spataro G, Cevenini G, Messina G. Association between air changes and airborne microbial contamination in operating rooms. J Infect Public Health. 2019;12(6):827830.doi:10.1016/j.jiph.2019.05.010

16. Morawska L, Johnson GR, Ristovski ZD, Hargreaves M, Mengersen K, Corbett S, Chao CYH, Li Y, Katoshevski D. Size distribution and sites of origin of droplets expelled from the human respiratory tract during expiratory activities. Journal of Aerosol Science. 2009;40: 256-269

17. Johnson GR, Morawska L, Ristovski ZD, Hargreaves M, Mengersen K, Chao CYH, Wan MP, Xie X, Katoshevski D, Corbett S. Modality of human expired aerosol size distributions. Journal of Aerosol Science. 2011;42(12):839-851.

18. Howard RA, Lathrop GW, Powell N. Sterile field contamination from powered air-purifying respirators (PAPRs) versus contamination from surgical masks. Am J Infect Control. 2020 Feb;48(2):153-156. doi: 10.1016/j.ajic.2019.08.009. Epub 2019 Sep 10. 
19. Fryar CD, Kruszon-Moran D, Gu Q, Ogden CL. Mean Body Weight, Height, Waist Circumference, and Body Mass Index Among Adults: United States, 1999-2000 Through 2015-2016. Natl Health Stat Rep. 2018;(122):1-16.

20. Nikitin N, Petrova E, Trifonova E, Karpova O. Influenza virus aerosols in the air and their infectiousness. Adv Virol. 2014;2014:859090. doi:10.1155/2014/859090

\section{Tables}

Table 1: Experimental Microbial Data Results 


\begin{tabular}{|c|c|c|c|c|c|}
\hline $\begin{array}{l}\text { Experimental } \\
\text { Design }\end{array}$ & Masking & $\begin{array}{l}\text { Mean Colony } \\
\text { Forming Units }\end{array}$ & $\begin{array}{l}\text { Incidence } \\
\text { contamination }\end{array}$ & $\begin{array}{l}\text { Difference } \\
\text { from } \\
\text { unmasked }\end{array}$ & $\begin{array}{l}95 \% \mathrm{Cl} \text { for } \\
\text { Difference from } \\
\text { Unmasked }\end{array}$ \\
\hline \multirow[t]{5}{*}{ Sterile field } & EHMRwM & 0 & $0 / 16$ & -0.75 & -0.91 to -0.48 \\
\hline & EHMR & 0 & $0 / 16$ & -0.75 & -0.91 to -0.48 \\
\hline & N95 & 0 & $0 / 16$ & -0.75 & -0.91 to -0.48 \\
\hline & $\begin{array}{l}\text { Surgical } \\
\text { mask }\end{array}$ & 0 & $0 / 16$ & -0.75 & -0.91 to -0.48 \\
\hline & No mask & 1.87 & $12 / 16$ & $\begin{array}{l}\text { Reference } \\
\text { Value }\end{array}$ & Reference Value \\
\hline \multirow{5}{*}{$\begin{array}{l}\text { Anesthesia } \\
\text { field }\end{array}$} & EHMRwM & 0.0625 & $1 / 16$ & 0.06 & -0.14 to 0.30 \\
\hline & EHMR & 0.0625 & $1 / 16$ & 0.06 & -0.14 to 0.30 \\
\hline & N95 & 0 & $0 / 16$ & 0.00 & -0.20 to 0.20 \\
\hline & $\begin{array}{l}\text { Surgical } \\
\text { mask }\end{array}$ & 0 & $0 / 16$ & 0.00 & -0.20 to 0.20 \\
\hline & No mask & 0 & $0 / 16$ & $\begin{array}{l}\text { Reference } \\
\text { Value }\end{array}$ & Reference Value \\
\hline \multirow[t]{5}{*}{ Nursing field } & EHMRwM & 0 & $0 / 16$ & -0.06 & -0.30 to 0.14 \\
\hline & EHMR & 0.0625 & $1 / 16$ & 0.00 & -0.25 to 0.25 \\
\hline & N95 & 0.0625 & $1 / 16$ & 0.00 & -0.25 to 0.25 \\
\hline & $\begin{array}{l}\text { Surgical } \\
\text { mask }\end{array}$ & 0 & $0 / 16$ & -0.06 & -0.30 to 0.14 \\
\hline & No mask & 0.0625 & $1 / 16$ & $\begin{array}{l}\text { Reference } \\
\text { Value }\end{array}$ & Reference Value \\
\hline \multirow{5}{*}{$\begin{array}{l}\text { All fields } \\
\text { combined }\end{array}$} & EHMRwM & & $1 / 16$ & -0.69 & -0.87 to -0.35 \\
\hline & EHMR & & $2 / 16$ & -0.62 & -0.83 to -0.28 \\
\hline & N95 & & $1 / 16$ & -0.69 & -0.87 to -0.35 \\
\hline & $\begin{array}{l}\text { Surgical } \\
\text { mask }\end{array}$ & & $0 / 16$ & -0.75 & -0.91 to -0.48 \\
\hline & No mask & & $13 / 16$ & $\begin{array}{l}\text { Reference } \\
\text { Value }\end{array}$ & Reference Value \\
\hline
\end{tabular}

EHMRwM = elastomeric half mask respirator with surgical mask; EHMR = elastomeric half mask respirator only 
Table 2: Experimental Particle Results with ANOVA analysis

\begin{tabular}{|c|c|c|c|c|c|}
\hline Location & $\begin{array}{l}\text { Mask } \\
\text { Group }\end{array}$ & $\begin{array}{l}\text { Mean } 0.2 \mathrm{~mm}+ \\
\text { Particles count } / \text { feet }^{3}\end{array}$ & $\begin{array}{l}\mathrm{p}- \\
\text { value }\end{array}$ & $\begin{array}{l}\text { Mean } 2.0 \mathrm{~mm}+ \\
\text { Particles count } / \text { feet }^{3}\end{array}$ & $\begin{array}{l}\mathrm{p}- \\
\text { value }\end{array}$ \\
\hline \multirow{5}{*}{$\begin{array}{l}\text { Sterile Field } \\
\text { Location } 1\end{array}$} & EHMRwM & 952.49 & \multirow[t]{5}{*}{0.9998} & 71.48 & \multirow[t]{5}{*}{0.8762} \\
\hline & EHMR & 911.94 & & 61.12 & \\
\hline & N95 & 878.372 & & 46.8769 & \\
\hline & $\begin{array}{l}\text { Surgical } \\
\text { Mask }\end{array}$ & 931.11 & & 41.58 & \\
\hline & No Mask & 961.36 & & 60.92 & \\
\hline \multirow{5}{*}{$\begin{array}{l}\text { Anesthesia field } \\
\text { Location } 2\end{array}$} & EHMRwM & 970.26 & \multirow[t]{5}{*}{0.9871} & 25.34 & \multirow[t]{5}{*}{0.7701} \\
\hline & EHMR & 991.82 & & 22.31 & \\
\hline & N95 & & & & \\
\hline & $\begin{array}{l}\text { Surgical } \\
\text { Mask }\end{array}$ & 1043.80 & & 29.40 & \\
\hline & No Mask & 1193.82 & & 41.73 & \\
\hline \multirow{5}{*}{$\begin{array}{l}\text { Nursing field } \\
\text { Location } 3\end{array}$} & EHMRwM & 1018.87 & \multirow[t]{5}{*}{0.9990} & 81.59 & \multirow[t]{5}{*}{0.9636} \\
\hline & EHMR & 987.07 & & 75.29 & \\
\hline & N95 & & & & \\
\hline & $\begin{array}{l}\text { Surgical } \\
\text { Mask }\end{array}$ & 1033.07 & & 79.40 & \\
\hline & No Mask & 1080.71 & & 94.49 & \\
\hline
\end{tabular}

EHMRwM = elastomeric half mask respirator with surgical mask; EHMR = elastomeric half mask respirator only

\section{Figures}




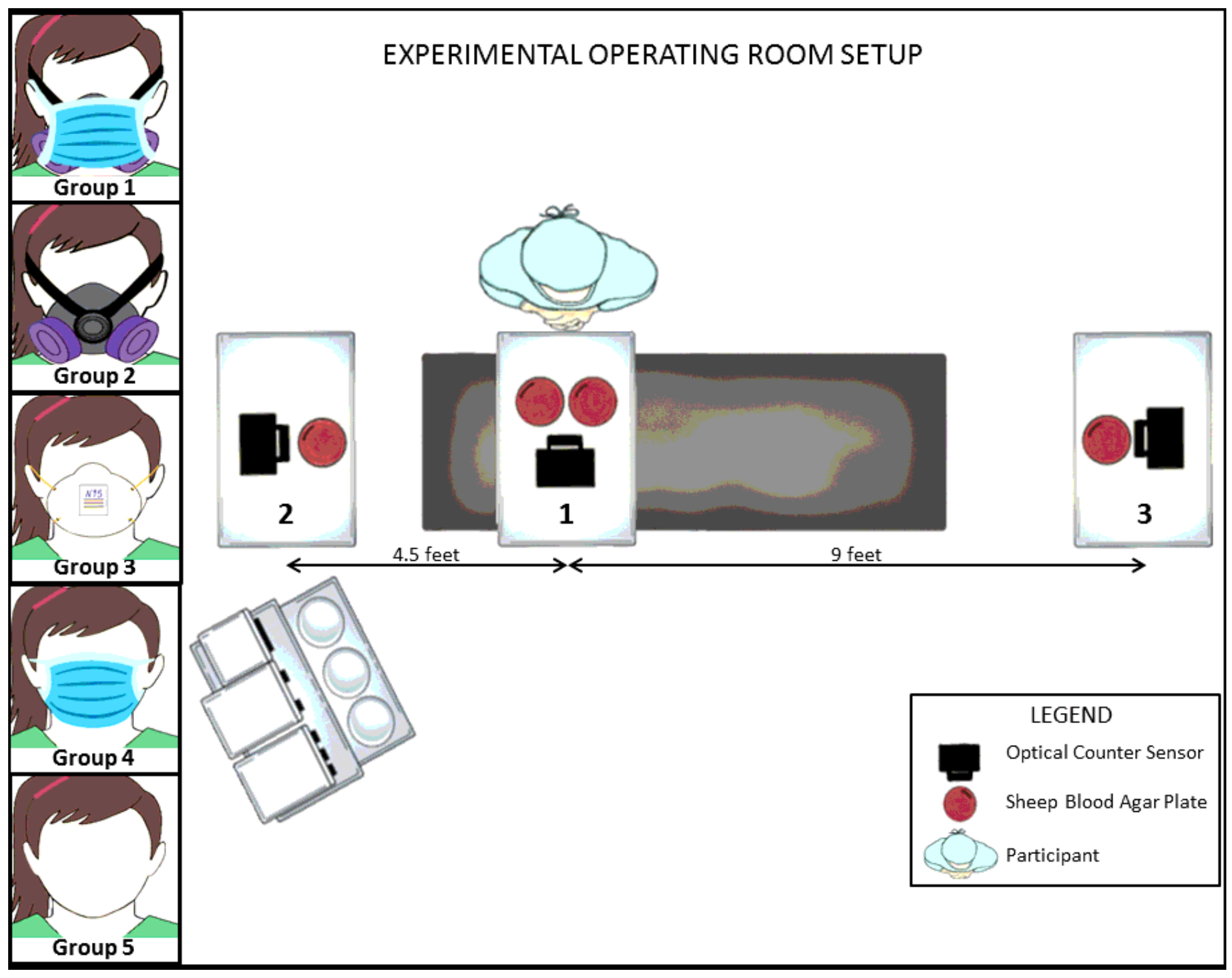

Figure 1

Experimental Room Setup. Experimental room setup showing participant, location of 3 Mayo stands creating experimental fields, and location of collection devices including sheep blood agar plates and optical counter sensors. Mayo stand $1=$ sterile field; Mayo stand $2=$ anesthesia field, Mayo stand $3=$ nursing field. The 4 masking groups are shown including: Group 1 = elastomeric half mask respirator covered by surgical mask (EMHRwM), Group 2 = elastomeric half mask respirator alone (EHMR), Group 3 = N95, Group 4 = standard surgical mask, and Group $5=$ unmasked. 


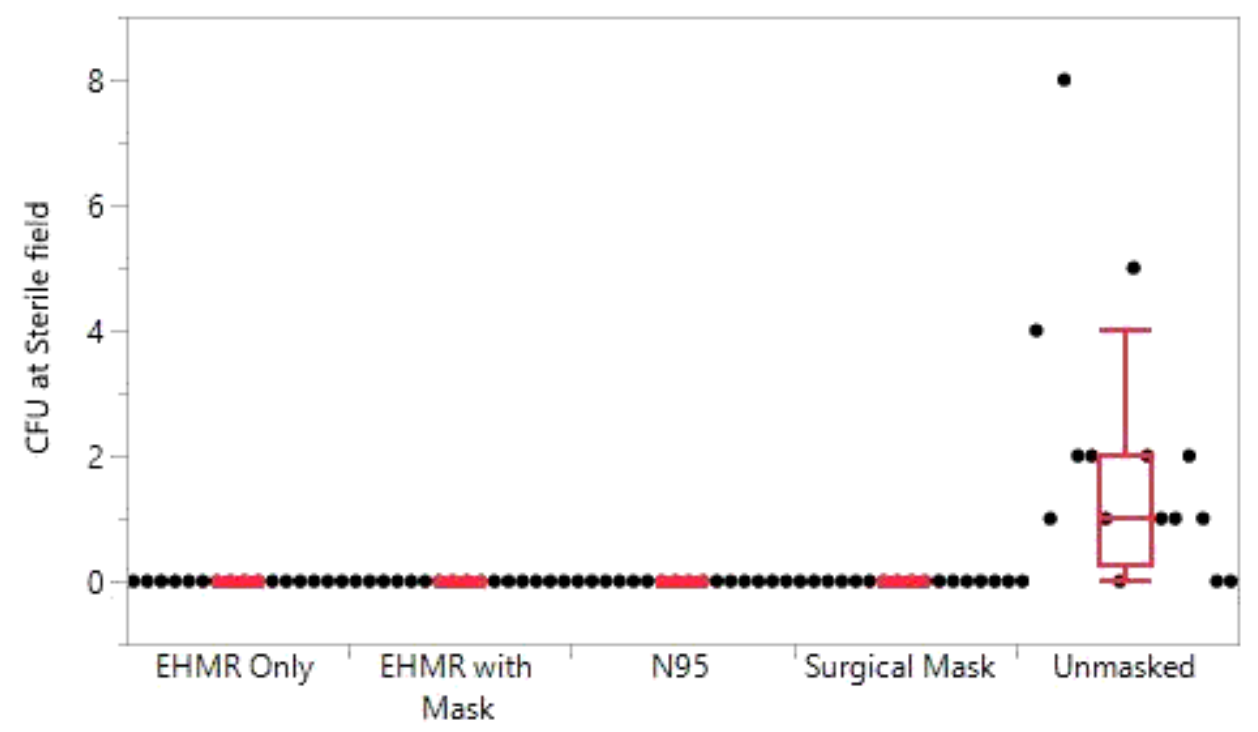

Mask Type

\section{Figure 2}

Sterile field results. Results and distributions of contamination by colony forming units on the agar settling plates are shown for each data point $(n=80)$. Box plot for all groups shows median at center line and quartiles $(n=16)$. Abbreviations: EHMR only = elastomeric half mask respirator only, EHMR with mask $=$ elastomeric half mask respirator covered by surgical mask

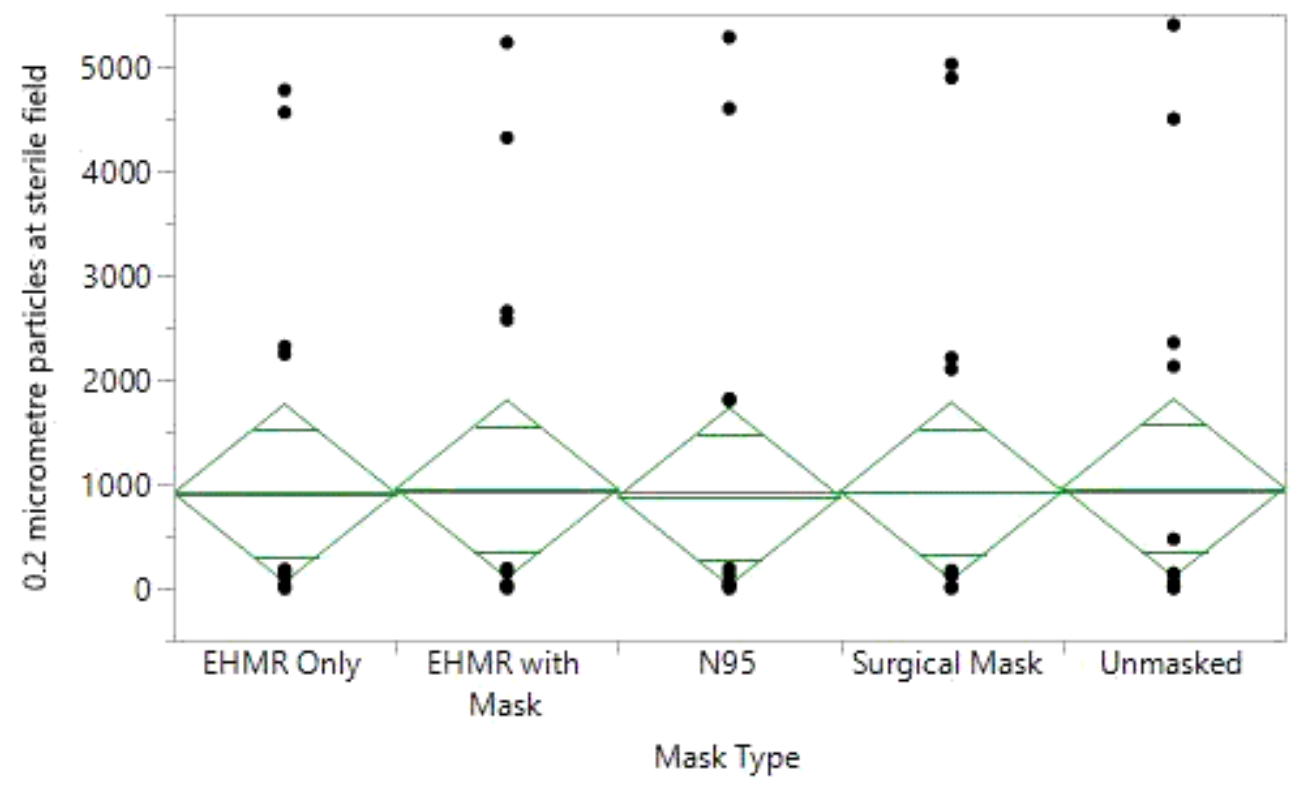

\section{Figure 3}

Particle results at sterile field. Results of total particle counts/feet3 for $0.2 \mu \mathrm{m}+$ aerosol particles at the sterile field. Mean diamonds shown for ANOVA analysis with the top and bottom of each diamond representing the (1-alpha)x100 confidence interval for each group comparing results between masks $(n=16)$. No significant difference in mean aerosol particle creation between masks. Abbreviations: EHMR with mask = elastomeric half mask respirator covered by surgical mask 